\title{
Digital economy and the models of income distribution in the society ${ }^{a}$
}

\author{
Askar Akaev ${ }^{1 *}$, Andrew Rudskoi ${ }^{2}$, and Tessaleno Devezas ${ }^{3}$ \\ ${ }^{1}$ Moscow State University, 119991 Leninskie Gory 1, Russian Federation \\ ${ }^{2}$ Peter the Great St. Petersburg Polytechnic University, 195251 Polytechnicheskaya st. 29, Russian \\ Federation \\ ${ }^{3}$ Atlantica School of Management Sciences, Health, IT \& Engineering C-MAST (Center for \\ Aerospace Science and Technologies), 2730-036 Atlantica, Fabrica da Polvora de Barcarena, Portugal
}

\begin{abstract}
Digital technologies, robotic automation and artificial intelligence are becoming the main drivers of technological and economic development. In this regard, it is quite natural that the demand for justification of such threats for the employment market appears, and also the question arises whether it is possible to foresee and analyze the level of inequality and distribution of income in the society where the proportion of artificial intellectual systems in creating new costs will be exceptionally large.
\end{abstract}

NBIC - technological revolution has led to creating highly-efficient digital technologies, intellectual computers and robots which are able to generate major changes in industrial forces many times superior to the achievements of the third industrial revolution based on microelectronics and informational technologies. Thatiswhythe world is talking about the fourth industrial revolution [1] and creating the Industry 4.0 [2]. The basic infrastructure of Industry 4.0 is industrial internet [3] - a digital platform which provides for effective cooperation of all objects of industrial production on the basis of the Internet. Simultaneously a multifunctional digital information technology has appeared which is designated for reliable account of assets and operations with them - Blockchaintechnology, able to become a reliable economic software in the Internet maintaining online payments, decentralized digital exchange of assets, release and execution of "clever contracts" [4]. Internet-technologies enable total automatization of the process of manufacturing goods starting from production of utilities and assembly works up to making electronic orders and delivering finished products to end-consumers, completely forcing human labor out of the production field. As digital technologies and platforms play the key role in the Industry 4.0 and in general in the new digitalized economy it is no wonder that transition to "Digital Economy" is being mentioned lately with increasing frequency.

One of the main innovations created by NBIC - technological revolution - is, without any doubt, nanochips, biochips and quantum computers [5]. They have significantly raised the computing capacity of computers which has led to breakthrough achievements in the

\footnotetext{
${ }^{\mathrm{a}}$ The article is prepared with financial support from the Russian Science Foundation (Grant No. 1818-00099)

*Corresponding author: askarakaev@mail.ru
} 
field of machine education and artificial intelligence (AI) [6]. It has become possible to create intellectual computers and robots which are able to cooperate with the human being, study and improve in the process of production activity.

Three main production technologies lie in the basis of producing goods within the framework of the Industry 4.0 or digital economy: automatized system of three dimensional digital design of complicated systems; additive technologies of layered growth (3Dprinting) of complicated objects on the basis of their three dimensional digital models; intellectual industrial robots. All these technologies give unprecedented flexibility to the Industry 4.0 thanks to the easiness with which parameters of product design can be changed using digital program methods both at the design stage and at the production stage. Thus, the Industry 4.0 or digital economy solves the problem of transition from the mass production of standard goods to creating qualitative goods and services meeting individual requirements and preferences. In its turn it conforms with the tendency of moving to variety of goods and services, to expanding their assortment, that is, it takes into account the consumers' behavior [7].

It goes without saying that the digital economy doesn't exist apart from the real economy. Digital economy is the developed real economy in which the key role is played by digital technologies and platforms that are aimed at increasing the productivity of factors, optimizing equipment operation, minimizing consumption of materials and resources, improving the quality of goods as well as increasing the accuracy of forecast of consumers' demand.

At the same time digital technologies also have disadvantages, intensive labor saving is most important of them. Digital economy will create very few new working places and destroy many jobs including entire professions [1]. Erik Brynjolfsson and Andrew McAfee, the Massachusetts Institute of Technology scientists claim: "The XXI century economy will qualitatively change. Mass replacement of qualified labor with capital will begin and, as a consequence, there will be a sharp decrease of labor activity" [8]. As you can see, new technologies come laden with the evidences of the new quality of growth but also they hold the serious danger of releasing a great number of employed people from the production field and forming a new structure of the entire employment market. The actuality of such a threat is demonstrated by the increased volume of publications about potential social consequences of the new technical revolution [9-12]. In this regard, it is quite natural that the demand for justification of such threats for the employment market appears, and also the question arises whether it is possible to foresee and analyze the level of inequality and distribution of income in the society where the proportion of artificial intellectual systems in creating new costs will be exceptionally large.

As a first step we suggest using the following model of labor employment and income taking into account technological replacement of working places.

$$
L(t)=\lambda \cdot\left(\frac{k}{\gamma}\right)^{\frac{1}{(1-\theta)(1-\tilde{\alpha}+\delta)}} \cdot K(t)^{\frac{1-\tilde{\alpha}-\theta(1-\tilde{\alpha}+\delta)}{(1-\theta)(1-\tilde{\alpha}+\delta)}},
$$

where $L(t)$ - is the number of workers and office staff employed; $K(t)$ - physical capital; $\lambda=\alpha^{\frac{1}{1-\theta}}-$ normalizing coefficient; $\theta-$ the parameter which characterizes the efficiency of education $(0<\theta \leq 1)$; $\alpha$ - normalizing coefficient; $\delta$ - capital input-output coefficient. If we set the constant present value in model (1) $\tilde{\alpha}=\alpha_{0}=0.38$ then, using this model, we can calculate the predictive dynamics of the potential number of working places in the USA economy $-L_{p}(t)$. Its diagram is presented in Fig. 1. 


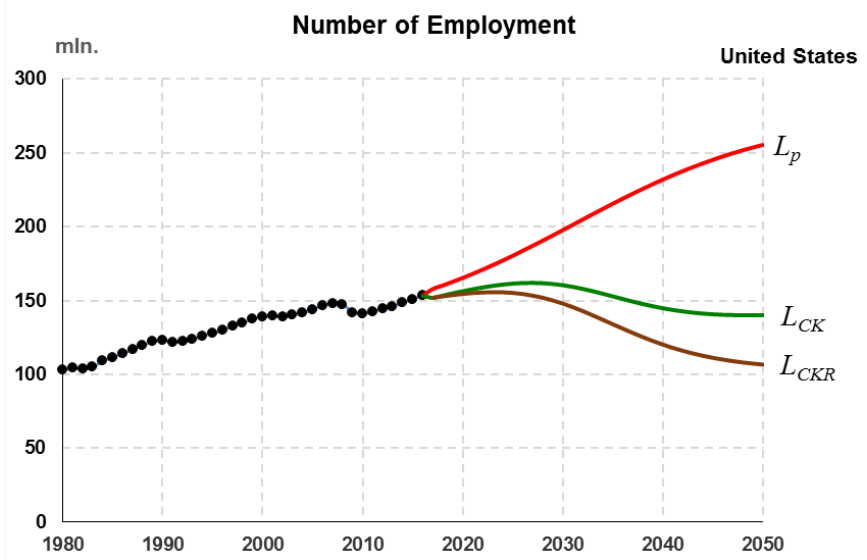

Fig. 1. The expected number of the people employed in the USA economy taking into account technological replacement of working places $\left(L_{C K}\right)$ and robotization of production $\left(L_{C K R}\right)$.

D. Acemoglu and P. Restrepo analyzed the USA labor market and determined that there is an empirical regularity: the appearance of one new robot for 1000 workers reduces employment - even if it increases in related branches - by $0.18 \%$ and the average salary reduces by $0.25 \%$ [13]. Later the same authors specified the indicated numbers to the higher side: employment is reduced to $0.34 \%$, and wages are reduced to $0.5 \%$. These empirical regularities are formalized in the following way:

$$
\begin{aligned}
& \text { a) } L_{C K R}(t)=L_{C K}(t) \cdot\left[1-\varepsilon_{L} \cdot\left(R(t)-R_{0}\right)\right], T_{0}=2018 \\
& \text { b) } \bar{\omega}(t)=\bar{\omega}_{0} \cdot\left[1-\varepsilon_{\omega} \cdot\left(R(t)-R_{0}\right)\right] \cdot \exp \left[\bar{q}_{p} \cdot\left(t-T_{0}\right)\right]
\end{aligned}
$$

Here $\bar{\omega}_{0}$ is the average annual salary of an employee in the USA in the moment $T_{0}$ (in the USA in $2016 \bar{\omega}_{0}=60$ thousand dollars); $\bar{q}_{p}$ - the average expected inflation rates which can be taken as equal to $2 \%$ per year (that is $\bar{q}_{p}=0.02$ ); $R_{0}=1.88 \mathrm{mln}$ robots used in the USA economy by the beginning of $2018 ; \quad \varepsilon_{L}=(0.18 \div 0.34) \cdot 10^{7}$ and $\varepsilon_{\omega}=(0.25 \div 0.5) \cdot 10^{-7}-$ empirical coefficients.

As $\bar{\omega}(t)(2 \mathrm{~b})$ isthe nominal average annual expected salary of one worker per year, the expected dynamics of the total annual income of all workers employed in the economy can be calculated using both the empirical regularities (2):

$$
\bar{Y}_{p h}(t)=\bar{\omega}(t) \cdot L_{C K R}(t)
$$

Additional reduction of working places caused by robotic automation of production and calculated with the help of the formula (2a) isreflectedbythecurve $L_{C K R}(t)$ inFig. 1. As you can see in this figure, digital technologies reduce four times more working places than robots (if we take $\varepsilon_{L}=0.34 \cdot 10^{-7}$, then - two times more) though we can witness for ourselves the work of robots when the action of digital technologies takes place in the real world. 
Now we address the work [14] in which, on the basis of the general statistic data, it was shown that distribution of the annual income of families with one and two working parents is well enough described by the exponential and Rayleign distribution laws:

$$
\begin{aligned}
& \text { a) } Y_{p h 1}=\frac{1}{r_{m 1}} \cdot \exp \left(-\frac{r}{r_{m 1}}\right) \\
& \text { b) } Y_{p h 2}=\frac{1}{r_{m 2}^{2}} \cdot \exp \left(-\frac{r}{r_{m 2}}\right),
\end{aligned}
$$

where $r$ is the annual family income in thousands of US dollars; $r_{m 1}$ and $r_{m 2}$ - mathematic expectations (average values) of family income. At that, it turned out that these distributions are fair for the income up to 120 thousand US dollars.

The distribution of income of rich families with the income more than 120 thousand dollars, as expected, turned out to be a power parameter - like the Pareto principle with the power coefficient $h=2.7$ :

$$
Y_{s p}(t, r)=\frac{h(t)-1}{Y_{s p_{0}}} \cdot\left(\frac{Y_{s p_{0}}}{r}\right)^{h(t)},
$$

where $Y_{s p_{0}}$ is the lower limit of income of rich families. According to our calculations the numerical values of parameters turned out to be equal to: $h=2.5$ for $2017 ; Y_{s p_{0}}=570$ thousand dollars. As we can see they have significantly changed during the last 20 years.

Besides, we have empirically determined that $h(t)$ is inversely proportional to $\tilde{\alpha}(t)$ :

$$
h(t)=\frac{h_{1}}{\tilde{\alpha}(t)}, h_{1}=\text { const } .
$$

Using the known data of the Pareto factor $h(t)$ we have determined the value $h_{1}=0.95$ . At that, $h(t)$ decreasing, asymptotically tends to the value of 2 .

The total income of private households $\bar{Y}_{p h}(t)$ defined by us earlier (3) is distributed between households with one and two workers:

$$
Y_{p h}(t, r)=\bar{Y}_{p h}(t) \cdot\left[v_{1}(t) \cdot Y_{p h_{1}}(r)+v_{2}(t) \cdot Y_{p h_{2}}(r)\right],
$$

Where $v_{1}$ and $v_{2}$ are shares of families with one and two workers and $v_{1}=1-v_{2}$. It is known that in 1996 theincomeof American households could be well described by approximation $0.45 \cdot Y_{p h_{1}}+0.55 \cdot Y_{p h_{2}}[14]$. In the $2010 \mathrm{~s}$ there already was the correlation $0.5 \cdot Y_{p h_{1}}+0.5 \cdot Y_{p h_{2}}$. 
The peak of women's economic activity in the USA came to 2000 when $60 \%$ of them worked equally with men [15]. Since then this indicator continues decreasing. As a result of intensive technological replacement of working places the number of families with two workers $v_{2}$ will decrease from now forward. It is quite logical to admit that this will happen according to the logistic law:

$$
v_{1}=\frac{v_{10}}{v_{10}+\left(1-v_{10}\right) \cdot \exp \left[-\vartheta_{v} \cdot\left(t-T_{0 v}\right)\right]},
$$

where $v_{10}, \vartheta_{v}$ are constant parameters. Let us suppose that by 2050 the absolute majority of families will have one worker, then, knowing that in the 2010 's $v_{10} \cong 0.5$, out of (8) we determine: $\vartheta_{v} \cong 0.067$.

Thus, we have defined the distribution of family income of the middle class including poor (7) and also rich families (5). Their mathematical expectations are important for comparative study; it is not hard to obtain them from the above mentioned distributions:

$$
\begin{aligned}
& \text { a) } r_{m p h}(t)=v_{1}(t) \cdot r_{m 1}+2 v_{2}(t) \cdot r_{m 2}=\left[v_{1}(t)+2 z \cdot v_{2}(t)\right] \cdot r_{m 1} \\
& \text { b) } r_{m s p}(t)=\frac{h(t)-1}{h(t)-2} \cdot Y_{s p 0} ; r_{m 2}=z \cdot r_{m 1}
\end{aligned}
$$

Here is the coefficientz taking into account difference in salaries of men and women in families. If their salaries are equal then $z=1$.

As $r_{m 1}$ we can take the average annual expected salary of a worker which we have already determined $(2 b)$ :

$$
r_{m 1}=\bar{\omega}_{0} \cdot\left[1-\varepsilon_{\omega} \cdot\left(R(t)-R_{0}\right)\right] \cdot \exp \left[\bar{q}_{p} \cdot\left(t-T_{0}\right)\right],
$$

This average income can nominally increase slightly, although in real terms it will only decline. As for rich families their average income (9b) will only grow because the Pareto factor $h(t)$ will decrease, asymptotically tending to 2 , and $Y_{s p_{0}}$ will slowly grow but we don't know the regularity of its growth.

Let us introduce a crude measure of inequality as the relation of the average income of rich families $(9 b)$ to the average income of families from the middle class including poor ones $(9 \mathrm{a})$ :

$$
\xi(t)=\frac{r_{m s p}(t)}{r_{m p h}(t)}=\frac{h(t)-1}{h(t)-2} \cdot \frac{Y_{s p_{0}}}{\left[v_{1}+2 z \cdot\left(1-v_{1}\right)\right] \cdot r_{m 1}},
$$

Here, $h(t)$ is calculated using the formula (6), $v_{1}$ - the formula (8) and $r_{m 1}$ - the formula (10). Thegrowthcurveof income inequality $\xi(t)$ calculated using the formula (11) with the conservative value $Y_{s p_{0}}=570$ thousand dollars and also the minimum value $\varepsilon_{\omega}=0.25 \cdot 10^{-7}$ is represented in Fig.2a. As you can see from the diagram, if drastic measures on redistributing income will not be taken, then inequality of income which represents more than a tenfold break already will grow and exceed a twenty-fold break in the 2030's, and by 2050 this value will exceed a fifty-fold break. And this is without taking into account the tendency to increase the lower limit of income of rich families $Y_{s p_{0}}$. 
a)

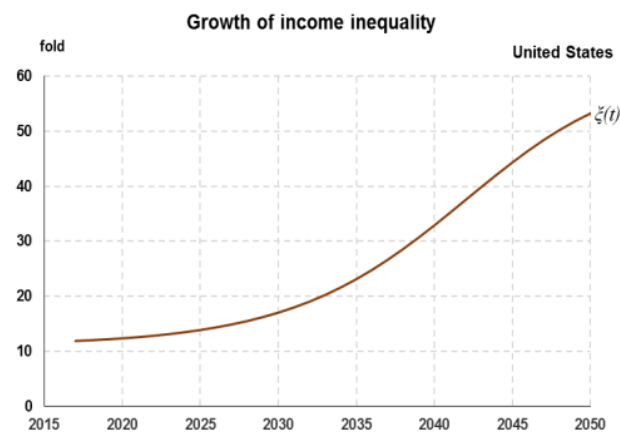

b)

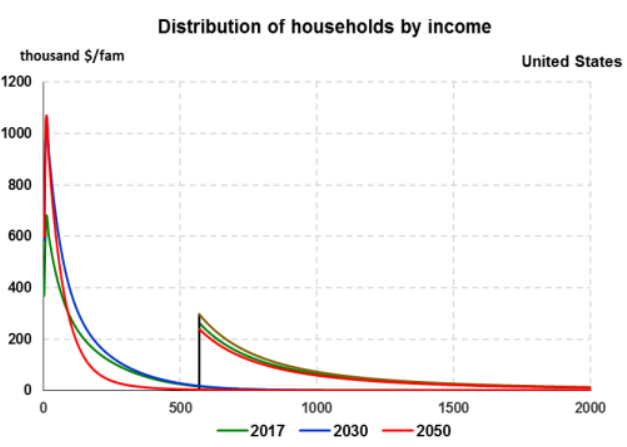

Fig. 2. Growth of inequality and polarization of income of the USA population.

The polarization of income is especially well seen in Fig. $2 b$ where the curves of distributing the annual income of middle class representatives are demonstrated, including poor ones (in Fig. $2 b$ - to the left) and also rich ones (in Fig. $2 b-$ to the right); the curves are built relatively using the formulas (7) and (5) for 2017, 2030 and 2050. As you can see, families with the average income within the limits of 300 thousand dollars to 600 thousand dollars will practically disappear by 2050 . This speaks of the devastation of the middle class from the society of the future, which at all times has been the backbone of democracy and stability in society.

In his fundamental book "The Great Divide", Joseph Stiglitz, the Nobel prizewinner, has disclosed to the fullest extent the true picture of income inequality in the USA and polarization of the American society and its harmful effect on the American nation and the whole world [16]. He appeals to adopt real decisions for preserving the middle class: increase of taxation for corporations and rich people; more investments in education and healthcare and also in science; assistance for households and not for banks; repairing economy to the full employment. That's just the possibility of making such decisions in the era of the digital economy remains a big question.

\section{References}

1. K. Schwab, The Fourth Industrial Revolution (World Economic Forum, Cologne, 2016)

2. H. Kagermann, W. Wahlster, J. Helbig, Recommendations for implementing the strategic initiative INDUSTRIE 4.0. [online], Available at: http://www.acatech.de/fileadmin/user_upload/Baumstruktur_nach_Website/Acatech /root/de/Material_fuer_Sonderseiten/Industrie_4.0/Final_report_Industrie_4.0_acce ssible.pdf (2013)

3. S. Greengard, The Internet of Things (The MIT Press, Cambridge, 2015)

4. M. Swan, Blockchain: Blue-print for a New Economy (O'Reilly Media, Sebastopol, 2015)

5. T. Devezas, J. Leitão, A. Sarygulov A., Industry 4.0 - Entrepreneurship and Structural Change in the New Digital Landscape (Springer International Publishing, Cham, 2017)

6. R. Kurzweil, How to Create a Mind: The Secret of Human Thought Revealed, (Brilliance Audio, New York, 2012) 
7. P. Saviotti, Journal of Evolutionary Economics, 11 (2001)

8. E. Brynjolfsson, A. McAfee, The Second Machine Age: Work, Progress and Prosperity in a Time of Brilliant Technologies (W.W. Norton \& Company New York, 2014)

9. E. Jacobs, What Do Trends in Economic Inequality Imply for Innovation and Entrepreneurship? [online], Available at: http://cdn.equitablegrowth.org/wpcontent/uploads/2016/02/16094329/021616-innovation-jacobs.pdf (2016)

10. C. M. Mody, Responsible Innovation: The 1970s, Today, and the Implications for Equitable Growth [online], Available at: http://cdn.equitablegrowth.org/wpcontent/uploads/2016/02/04175810/020816-resp-innov.pdf (2016)

11. G. Valenduc, P. Vendramin, ETUI Working paper (2016)

12. C. Degryse, ETUI Working paper (2016)

13. D. Acemoglu, P. Restrepo, NBER Working Paper No. 23285 (2017)

14. A. Dragulesku, V. M. Yakovenko, Physica A., 299 (2001)

15. M. Ford, Basic books, 2 (2015)

16. J. E. Stiglitz, The Great Divide: Unequal Societies and What We can Do About Them (W.W. Norton \& Company, New York, 2015) 